\title{
STUDI PENENTUAN TARIF TOL RENCANA RUAS JALAN TOL BANDA ACEH - SIGLI
}

\author{
Qasim Hisbul Wathan $^{1)}$, Muhammad Isya ${ }^{2)}$, Sugiarto Sugiarto ${ }^{3)}$ \\ ${ }^{1)}$ Magister Teknik Sipil, Universitas Syiah Kuala \\ ${ }^{2,3)}$ Jurusan Teknik Sipil, Universitas Syiah Kuala \\ Corresponding email: qasim101090@gmail.com
}

DOI: http://dx.doi.org/10.29103/tj.v9i2.223

(Received: May 2019 / Revised: July 2019 / Accepted: August 2019)

\begin{abstract}
Abstrak
Pemerintah Indonesia sedang aktif melakukan pembangunan insfrastruktur transportasi tidak terkecuali di Pulau Sumatera diantaranya pembangunan tol ruas Jalan Banda Aceh - Binjai. Tol Aceh ini, terdiri dari 4 ruas jalan dengan panjang total $455 \mathrm{~km}$ yang terdiri dari ruas jalan tol Banda Aceh - Sigli $75 \mathrm{~km}$, ruas jalan tol Sigli Lhokseumawe $135 \mathrm{~km}$, ruas jalan tol Lhokseumawe - Langsa $135 \mathrm{~km}$, dan ruas jalan tol Langsa-Binjai $110 \mathrm{~km}$. Pembangunan ruas tol pertama dimulai pada koridor ruas jalan Banda Aceh - Sigli, jalan tol ini nantinya akan menjadi jalan tol pertama di Aceh, sehingga diperlukan penelitian terhadap tarif tol rencana untuk ruas jalan tersebut. Penelitian ini bertujuan untuk mengetahui tarif tol berdasarkan $70 \%$ dari Besar Keuntungan Biaya Operasional Kendaraan (BKBOK). Survey dilakukan untuk mendapatkan jumlah volume lalu lintas di jalan eksisting. Jenis kendaraan yang ditinjau hanya kendaraan golongan I, IIA dan IIB. Analisis biaya operasional kendaraan menggunakan metode Pacific Consultant International (PCI) 2000. Tarif dihitung berdasarkan $70 \%$ dari BKBOK untuk Golongan I (Light Vehicles) di dapat tarif sebesar Rp. 87,290 dari keuntungan BKBOK untuk Golongan IIA (Medium Heavy Vehicles) di dapat sebesar Rp. 215,395 dan untuk Golongan IIB (Heavy Vehicles) di dapat tarif sebesar Rp.193, 659 dari keuntungan BKBOK.
\end{abstract}

Kata kunci: Analisis, Tarif Tol, BOK, BKBOK

\begin{abstract}
Thus, Aceh Government is vigorously developing the transportation infrastructure, no exception on the island of Sumatra, one of which is the construction of Banda Aceh Binjai toll road. The toll road consists of four highways, with the total length of the toll roads is $455 \mathrm{~km}$ consisting of Banda Aceh - Sigli as $75 \mathrm{~km}$, Sigli - Lhokseumawe as $135 \mathrm{~km}$, Lhokseumawe - Langsa as $135 \mathrm{~km}$, and Langsa - Binjai as $110 \mathrm{~km}$. The construction of the first toll road was started on the Banda Aceh - Sigli road corridor which will be the first toll road in Aceh. Therefore, the research is needed to plan the toll rates for the road. This research aims to examine the toll road rates based on $70 \%$ of The Amount Profit of Vehicle Operating Cost (BKBOK). Hence, the survey was conducted to get the number of traffic volume on the existing road. The types of vehicles reviewed are only type I, IIA and IIB. The analysis method of vehicle operating costs uses the Pacific Consultant International (PCI) (2000) method. The toll rates are calculated based on $70 \%$ of BKBOK, for type I (Light Vehicles) as Rp. Rp. 87,290 from BKBOK's profits, for type IIA (Medium Heavy Vehicles) as Rp. 215,395 and for type IIB (Heavy Vehicles) as Rp.193, 659 from BKBOK's profits.
\end{abstract}

Keyword: Analysis, toll rates, $B O K, B K B O K$

Studi Penentuan Tarif Tol Rencana Ruas Jalan Tol Banda Aceh - Sigli - Qasim Hisbul 


\section{Latar Belakang}

Peningkatan daya saing melalui pembangunan infrastruktur merupakan hal yang tepat, tidak terkecuali di Pulau Sumatera. Pembangunan infrastruktur sebagai prioritas utama merupakan pilihan yang logis dan strategis dalam meningkatkan daya saing Indonesia sekaligus untuk mengejar ketertinggalan, diantaranya pembangunan Ruas Jalan Tol Banda Aceh - Binjai. Berdasarkan Keputusan Menteri Pekerjaan Umum dan Perumahan Rakyat Republik Indonesia No. 248/KPTS/M/2015 tentang penetapan ruas jalan dalam jaringan jalan primer menurut fungsinya sebagai Jalan Arteri Primer (JAP) dan Jalan Kolektor-1 (JKP1) menerangkan bahwa status ruas jalan Batas Kota Banda Aceh - Sigli, untuk jalan eksisting tergolong kedalam jaringan Jalan Arteri Primer (JAP) dengan kewenangan pembinaan dikelompokkan kedalam status jalan Nasional.

Menurut Undang-undang Republik Indonesia Nomor 15 tahun 2005 tentang Jalan Tol, menjelaskan jalan tol adalah jalan umum yang merupakan bagian sistem jaringan jalan dan sebagai jalan nasional yang penggunanya diwajibkan membayar tol. Jalan tol itu sendiri memiliki kriteria yaitu dikhususkan bagi kendaraan atau transportasi yang memiliki sumbu lebih dari dua atau tidak dapat kurang dari dua, misalnya saja mobil truk, bus, dan lain sebagainya, asalkan tetap memenuhi kriteria khusus tersebut. Seperti sebutannya untuk jalan tol itu sendiri, yaitu jalan bebas hambatan, yang artinya jalan tol memiliki fungsi khusus dalam memperlancar lalu lintas. Berupaya memenuhi jalan khusus yang nantinya akan membantu pengendara transportasi untuk lebih mudah dalam perjalanan, maka jalan tol akan mempengaruhi upaya menanggulangi kelancaran berlalu lintas yang kian lama kian mahal solusinya. Untuk itu pemerintah berupaya memecahkan duduk masalah tersebut dengan adanya upaya pembangunan jalan tol antar daerah, maupun daerah berkembang. Tol Aceh ini, terdiri dari 4 ruas jalan dengan panjang total $455 \mathrm{~km}$ yang terdiri dari ruas Jalan Tol Banda AcehSigli $75 \mathrm{~km}$, ruas Jalan Tol Sigli - Lhokseumawe $135 \mathrm{~km}$, ruas Jalan Tol Lhokseumawe - Langsa $135 \mathrm{~km}$, dan ruas Jalan Tol Langsa - Binjai $110 \mathrm{~km}$. Pembangunan ruas tol pertama dimulai pada koridor ruas Jalan Banda Aceh Sigli, jalan tol ini nantinya akan menjadi jalan tol pertama di Aceh, sehingga diperlukan penelitian terhadap tarif tol rencana untuk ruas jalan tersebut.

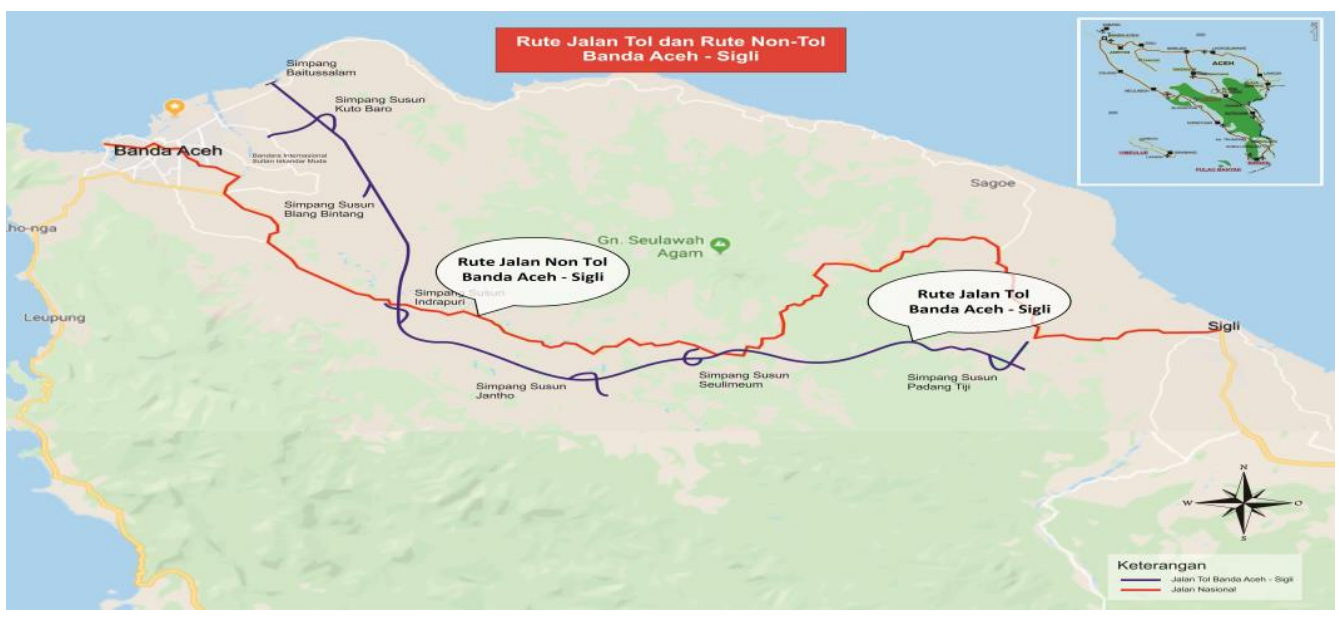

Gambar 1 Rute Jalur Ruas Jalan Tol Sigli - Banda Aceh (overlay pada map data (C) 2019 Google), Lokasi Kajian pada Rute 2 (line 2: warna biru) 


\section{Metode Penelitian}

Langkah kerja dalam penyusunan penelitian ini meliputi identifikasi masalah, persiapan awal dan studi literatur, pengumpulan dan pengolahan data, analisa tarif tol. Data yang dikumpulkan dalam penelitian berupa data primer dan data sekunder. Kemudian dilanjutkan pengamatan terhadap lalu lintas bertujuan untuk mendapatkan besarnya volume dan komposisi lalu lintas pada ruas jalan yang diteliti. Hasil dari survai volume lalu-lintas yang dilakukan kemudian akan didapat komposisi pergerakan kendaraan. Setiap jenis pergerakan kendaraan diekivalensikan ke dalam Satuan Mobil Penumpang (SMP) dan nilai konversi ekivalensinya.

Untuk volume lalu lintas pada jalan tol diasumsikan Menjadi 3 Skenario $70 \%, 60 \%$ dan $50 \%$ dari volume lalu lintas pada jalan eksisting akan beralih ke jalan tol. Kemudian dilanjutkan dengan menghitung nilai nilai kecepatan dan waktu tempuh yang diambil adalah untuk ruas jalan eksisting menggunakan metode license plate method dengan cara pencatatan nomor polisi kendaraan, sedangkan untuk kecepatan pada ruas jalan tol menggunakan kecepatan rencana.

Setelah data terkumpul dilanjutkan dengan Perhitungan nilai waktu dan diteruskan dengan perhitungan Biaya Operasional Kendaraan (BOK) pada jalan tol dan jalan non tol dengan menggunakan metode Pacific Consultant International (2000). Setelah data Biaya Operasional Kendaraan (BOK) keduanya di dapatkan, selanjutkannya Perhitungan dan Analisa Besar Keuntungan Biaya Operasional Kendaraan (BKBOK), perhitungan tarif di batasi maksimum 70\% BKBOK

\subsection{Lokasi Penelitian}

Penelitian ini dilakukan pada ruas Jalan Tol Banda Aceh - Sigli dengan. masing-masing memiliki empat lajur efektif tanpa median (4/2 UD), dengan Lokasi survai adalah di Ruas Jalan Lambaro - Bts. Pidie pada KM. 09+000 KM, KM. 23+000, KM. 40+570, KM 77+000 Lokasi penelitian dapat dilihat pada Peta lokasi proyek pembangunan jalan tol lintas Banda Aceh-Sigli seperti diperlihatkan pada gambar 2

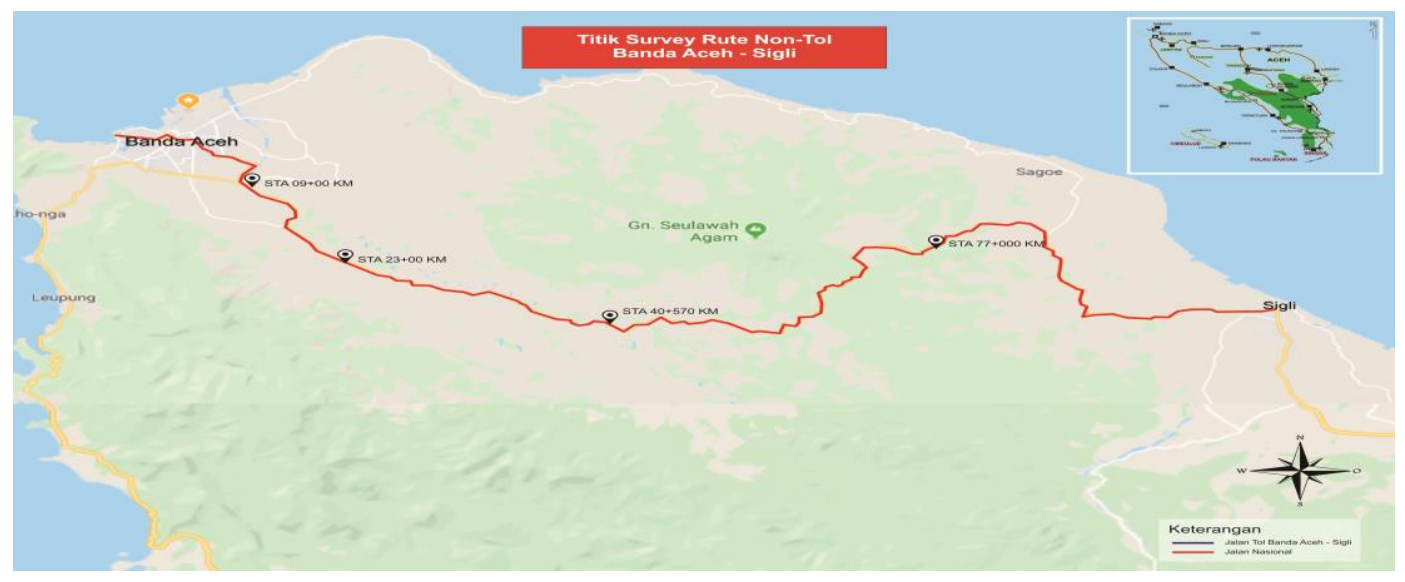

Gambar 2 Lokasi Titik Survey Lalu lintas Pada Ruas Jalan Banda Aceh - Sigli (overlay pada map data @ 2019 Google), Lokasi Kajian pada (line: warna Merah) 


\subsection{Pengamatan dan Pengumpulan Data}

Pengamatan terhadap lalu lintas bertujuan untuk mendapatkan besarnya volume dan komposisi lalu lintas pada ruas jalan yang diteliti. Survai pengamatan dilakukan selama empat hari, yaitu pada hari Sabtu dan Minggu untuk mewakili aktifitas hari libur, Senin dan Kamis mewakili aktifitas hari kerja. Survai dilakukan selama 14 jam yang dimulai pukul 07.00-21.00 WIB dan pencatatan dilakukan setiap 15 menit, pada segmen jalan penelitian ini, ditempatkan 2 orang surveyor untuk mencatat pergerakan lalu lintas yang akan berganti shift jaga, sehingga total anggota survai adalah 10 orang. Hasil pencatatan akan didapat jumlah kendaraan yang melewati segmen jalan yang akan diklasifikasikan sesuai yang disyaratkan MKJI 1997. Hasil dari survai volume lalu lintas kemudian akan didapat komposisi pergerakan kendaraan. Setiap jenis pergerakan kendaraan diekivalensikan ke dalam Satuan Mobil Penumpang (SMP) dan nilai konversi ekivalensinya. Berdasarkan hasil pengamatan dilapangan, volume lalu lintas yang digunakan adalah volume lalu lintas puncak dari hari pengamatan selama empat hari. Data yang dikumpulkan dalam penelitian berupa data primer dan data sekunder. Data primer adalah data yang didapatkan secara langsung dengan melakukan survei di lokasi penelitian, sedangkan data sekunder adalah data pendukung, data tersebut dapat diperoleh melalui instansi terkait.

\subsection{Biaya Operasional Kendaraan (BOK)}

Menurut pedoman yang dikeluarkan oleh Departemen Pekerjaan Umum (2005), tentang Pedoman Perhitungan Biaya Operasi Kendaraan menyatakan bahwa biaya operasional kendaraan adalah biaya total yang dibutuhkan untuk mengoperasikan kendaraan pada suatu kondisi lalu lintas dan jalan untuk satu jenis kendaraan per kilometer jarak tempuh (dalam Rp/km). kecepatan rendah menunjukkan biaya operasi yang tinggi karena bertambahnya pengereman, percepatan, dan keausan kendaraan. Jika arus lancar, kecepatan dapat meningkat, mengakibatkan biaya operasi meningkat di satu sisi, tetapi di sisi lain menghindari biaya operasi tambahan seperti yang disebabkan pada kasus kemacetan lalu-lintas.

Biaya operasi kendaraan terdiri dari dua komponen utama yaitu biaya tidak tetap (variable cost atau running cost) dan biaya tetap (standing cost atau fixed cost), (Tamin, 2008). Untuk menghitung biaya operasional kendaraan perlu diketahui daftar harga satuan komponen-komponen yang digunakan sebagai unitunit perhitungan biaya operasional kendaraan. Persamaan untuk menghitung biaya operasional kendaraan dapat dilihat pada persamaan 1

$$
B O K=B T T+B T
$$

Di mana BOK yang artikan biaya operasional kendaraan dengan satuan (rupiah $/ \mathrm{km}$ ), BTT adalah biaya tidak tetap dengan satuan (rupiah $/ \mathrm{km}$ ) dan BT adalah biaya tetap dengan satuan (rupiah/km).

Menurut metode Pacific Consultant International (2000), perhitungan biaya tetap merupakan penjumlahan dari komponen-komponen yang terdiri dari biaya penyusutan, biaya awak kendaraan, biaya asuransi dan biaya bunga modal. untuk biaya tetap dapat dilihat pada persamaan 2

$$
B T=B p i+B K i
$$

Di mana BT yang artikan biaya tetap dengan Satuan (rupiah/km), Bpi adalah biaya depresiasi/penyusutan kendaraan dengan satuan (rupiah/km), BKi adalah biaya awak kendaraan dengan satuan (rupiah/km).

Studi Penentuan Tarif Tol Rencana Ruas Jalan Tol Banda Aceh - Sigli - Qasim Hisbul Wathan, Muhammad Isya, Sugiarto Sugiarto 
Menurut metode Pacific Consultant International (2000) biaya tidak tetap (variable cost atau running cost) merupakan penjumlahan dari komponenkomponen yang terdiri dari konsumsi bahan bakar, biaya oli, biaya konsumsi suku cadang, biaya upah tenaga pemeliharaan dan biaya ban. untuk biaya tetap dapat dilihat pada persamaan 3

$$
B T T=B i B B M j+B O i+B p i+B u i+B B i
$$

Di mana BTT yang artikan biaya tidak tetap dengan satuan (rupiah/km), BiBBMj adalah biaya konsumsi bahan bakar minyak dengan satuan (rupiah/km), BOi adalah biaya konsumsi oli dengan satuan (rupiah/km), Bpi adalah biaya pemeliharaan (rupiah/km), Bui adalah biaya upah tenaga dengan satuan (rupiah/km), BBi adalah biaya konsumsi ban dengan satuan (rupiah/km).

\subsection{Nilai Waktu}

Nilai waktu didefinisikan sebagai nilai uang yang rela dikeluarkan oleh seseorang, dalam hal ini pengguna jalan tol, untuk menghemat/memperoleh suatu unit waktu dari hasil keputusannya untuk menggunakan jalan alternatif tol ketimbang jalan biasa (LAPI-ITB, 1997). Perhitungan nilai waktu dalam penelitian ini salah satunya menggunakan nilai waktu dasar seperti pada Tabel 1 .

Tabel 1 Nilai Waktu Dasar Setiap Golongan Kendaraan

\begin{tabular}{cccc}
\hline \multirow{2}{*}{ Rujukan } & \multicolumn{3}{c}{ Nilai Waktu (Rp./jam/kendaraan) } \\
\cline { 2 - 4 } & Golongan I & Golongan IIA & Golongan IIB \\
\hline PT Jasa Marga (1990-1996) & 12.287 & 18.534 & 13.768 \\
\hline Padalarang-Cileunyi (1996) & $3.385-5.425$ & $3.827-8.344$ & 5.716 \\
\hline Semarang (1996) & $3.411-6.221$ & 14.541 & 1.506 \\
\hline IHCM (1995) & 3.281 & 18.212 & 4.971 \\
\hline PCI (1979) & 1.341 & 3.827 & 3.152 \\
\hline JIUTR Northern Extension (PCI, 1989) & 7.067 & 14.670 & 3.659 \\
\hline Surabaya-Mojokerto (JICA, 1991) & 8.880 & 7.960 & \\
\hline & Sumber: (LAPI-ITB 1997) &
\end{tabular}

Perhitungan Nilai Waktu pada suatu daerah dapat dilakukan dengan memilih nilai waktu yang terbesar diantara Nilai Waktu Dasar (basic value of time) seperti terlihat pada Tabel 1 yang dikoreksi menurut tingkat Produk Domestik Regional Bruto (PDRB) daerah tersebut seperti terlihat pada Tabel 2.

Tabel 2 Nilai Koreksi $\boldsymbol{k}$

\begin{tabular}{ccccc}
\hline Lokasi & $\begin{array}{c}\text { PDRB (juta } \\
\text { Rp.) }\end{array}$ & Jumlah Penduduk & $\begin{array}{c}\text { PDRB per } \\
\text { kapita (juta } \\
\text { Rp.) }\end{array}$ & Nilai Koreksi \\
\hline DKI Jakarta & 60.638 .217 & 9.113 .000 & 6,65 & 1,00 \\
\hline Jawa Barat & 60.940 .114 & 39.207 .000 & 1,55 & 0,23 \\
\hline Kodya Bandung & 6.097 .380 & 2.356 .120 & 2,59 & 0,39 \\
\hline Jawa Tengah & 39.125 .323 & 29.653 .000 & 1,32 & 0,20 \\
\hline Kodya Semarang & 4.682 .002 & 1.346 .352 & 3,48 & 0,52 \\
\hline Jawa Timur & 57.047 .812 & 33.844 .000 & 1,69 & 0,25 \\
\hline Kodya Surabaya & 13.231 .986 & 2.694 .554 & 4,91 & 0,74 \\
\hline Sumatera Utara & 21.802 .508 & 11.115 .000 & 1,96 & 0,29 \\
\hline Kodya Medan & 5.478 .924 & 1.800 .000 & 3,04 & 0,46 \\
\hline \multicolumn{5}{c}{ Sumber: (LAPI-ITB 1997) } \\
\end{tabular}


Dengan Nilai Waktu Minimum seperti pada Tabel 3 dihitung nilai waktu melalui persamaan 4 .

$$
N W=\operatorname{Maksimum}[(k x N W D) \cdot N W M]
$$

Dimana NW adalah Nilai Waktu dengan satuan (Rp./jam/kendaraan), $k$ adalah faktor koreksi sesuai tingkat pendapatan daerah (PDRB) perkapita seperti pada Tabel 2, NWD adalah Nilai Waktu Dasar dengan satuan (Rp./jam/kendaraan), seperti Tabel 1, dan $N W M$ adalah Nilai Waktu Minimum dengan satuan (Rp./jam/kendaraan) seperti terlihat pada Tabel 3.

Tabel 3 Nilai Waktu Minimum (Rupiah/Jam/kendaraan)

\begin{tabular}{ccccccc}
\hline \multirow{2}{*}{ Kabupaten/Kodya } & \multicolumn{3}{c}{ Jasa Marga } & \multicolumn{3}{c}{ JIUTR } \\
\cline { 2 - 7 } & Gol. I & Gol. IIA & Gol. IIB & Gol. I & Gol. IIA & Gol. IIB \\
\hline DKI Jakarta & 8.200 & 12.369 & 9.188 & 8.200 & 17.022 & 4.246 \\
\hline Selain DKI Jakarta & 6.000 & 9.051 & 6.723 & 6.000 & 12.455 & 3.107 \\
\hline \multicolumn{3}{c}{ Sumber: (LAPI-ITB 1997) }
\end{tabular}

\subsection{Penentuan Tarif Tol}

Biaya operasi kendaraan melalui jalan baru ditambah dengan pembayaran tarif harus lebih rendah dari pada biaya operasi kendaraan melalui alternatife jalan umum yang ada (Suhartono, dkk. 2010). Selisih BOK (alternatif) dan BOK $_{(\text {baru }}$ dinamakan sebagai Besar Keuntungan Biaya Operasi Kendaraan (BKBOK), penentuan tarif dibatasi maksimum $70 \%$ BKBOK, Nilai BKBOK, dapat dihitung dengan menggunakan persamaan 5

$$
B K B O K=\left(B O K_{a l t} x D_{a l t}-B O K_{t o l} x D_{t o l}\right)+\left\{\left(\frac{D_{a l t}}{V_{a l t}}-\frac{D_{t o l}}{V_{t o l}}\right) x T_{v}\right\}
$$

Di mana BKBOK adalah Besar keuntungan biaya operasi kendaraan dengan satuan (Rp), BOK $_{\text {alt }}$ adalah Biaya operasi kendaraan di jalan yang ada dengan satuan (Rp), $\mathrm{BOK}_{\text {tol }}$ adalah Biaya operasi kendaraan di jalan tol dengan satuan $(\mathrm{Rp}), \mathrm{D}_{\text {alt }}$ adalah Panjang jalan yang ada dengan satuan $(\mathrm{km}), \mathrm{D}_{\text {tol }}$ adalah panjang jalan tol dengan satuan $(\mathrm{km})$,Valt adalah kecepatan di jalan yang ada dengan satuan $(\mathrm{km} / \mathrm{jam})$, Vtol adalah kecepatan di jalan tol dengan satuan $(\mathrm{km} / \mathrm{jam}), \mathrm{Tv}$ adalah Nilai waktu kendaraan dengan satuan (Rp/jam).

\section{Hasil dan Pembahasan}

\subsection{Volume Lalu lintas}

Berdasarkan hasil dari survai volume lalu lintas Jalan Lambaro-Batas Pidie seperti diperlihatkan pada Gambar 3, kemudian akan diperoleh komposisi pergerakan kendaraan. Setiap jenis pergerakan kendaraan diekivalensikan ke dalam Satuan Mobil Penumpang (SMP) dan nilai konversi ekivalensinya dipergunakan untuk perhitungan. Berdasarkan hasil pengamatan di lapangan, volume lalu lintas yang digunakan adalah volume lalu lintas puncak dari hari pengamatan selama empat hari, maka di dapat volume Lalu lintas nya untuk titik survei Lambaro KM. 09+000. 


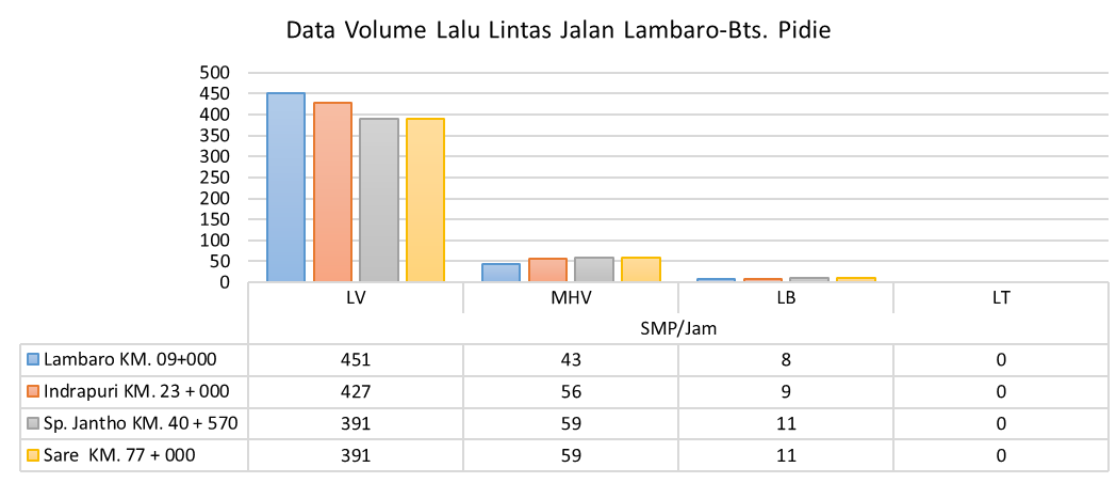

Gambar 3 Grafik Volume lalu lintas Jalan Lambaro-Bts. Pidie

Untuk volume lalu lintas pada jalan Tol diasumsikan berdasarkan 3 skenario yaitu 70\%, 60\%, dan 50\% dari volume lalu lintas pada jalan eksisting ruas Jalan Banda Aceh - Sigli akan menggunakan jalan tol, Pada kondisi yang sama setelah volume lalu lintas beralih ke jalan tol maka volume yang berada pada jalur exsisting akan berkurang, dapat dilihat pada Gambar 2

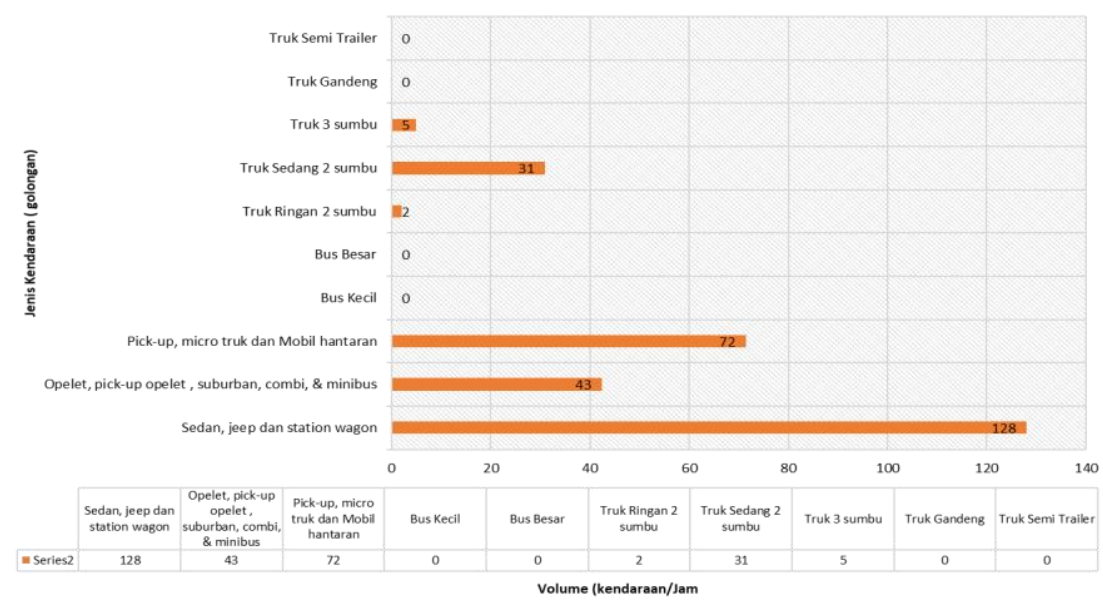

Gambar 2 Grafik Rekapitulasi Volume Lalu Lintas Jalan Tol Skenario 50\%

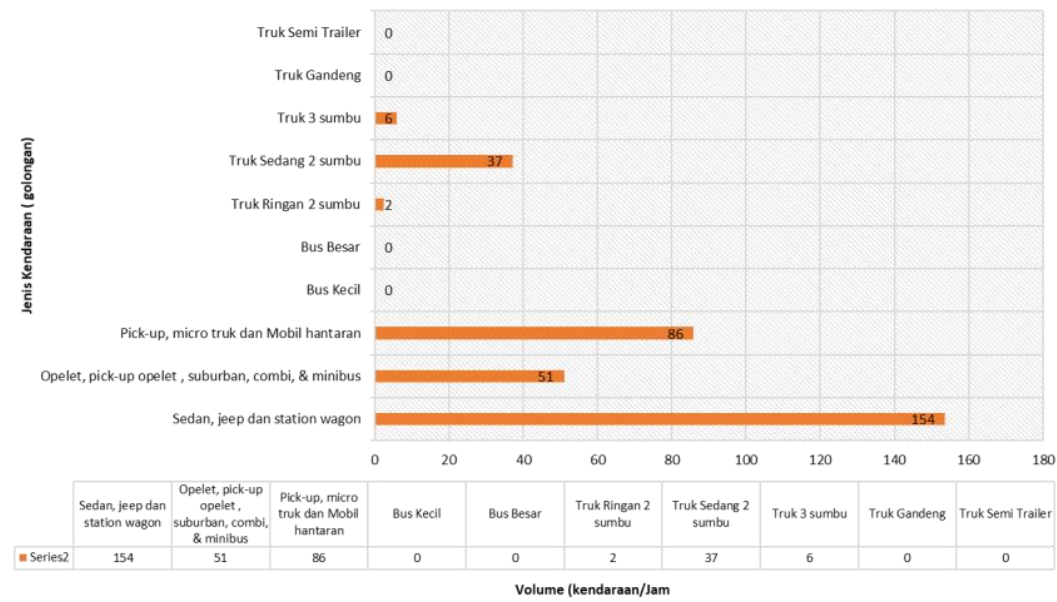

Gambar 3 Grafik Rekapitulasi Volume Lalu Lintas Jalan Tol Skenario 60\% 


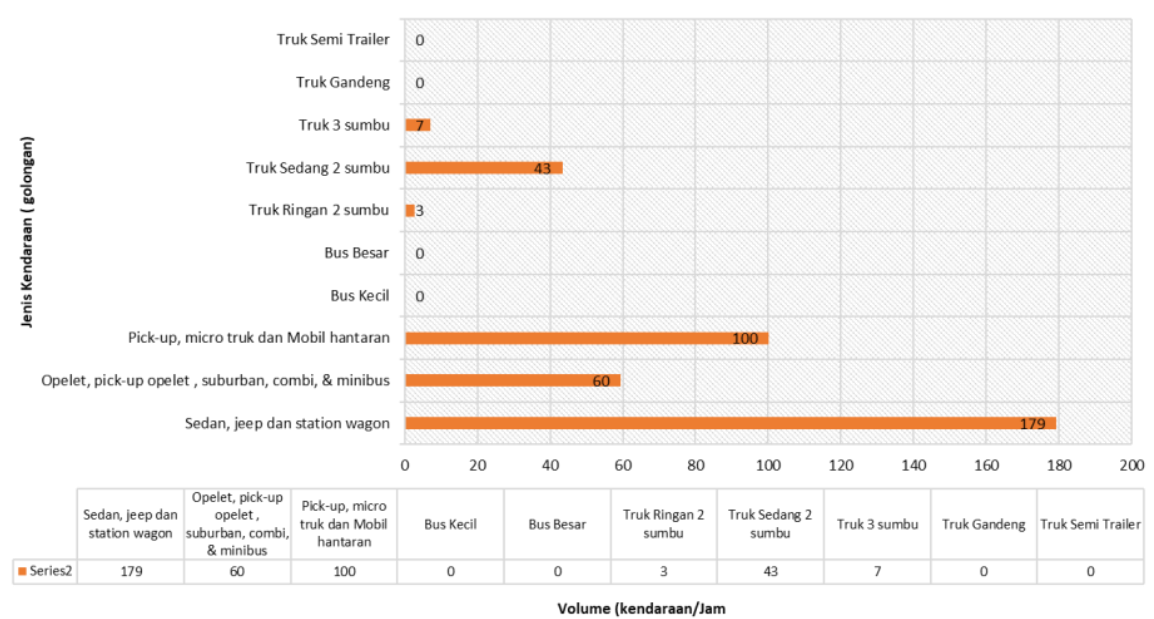

Gambar 4 Grafik Rekapitulasi Volume Lalu Lintas Jalan Tol Skenario 70\%

Manfaat pada arus lalu lintas pada jalur eksisting akan meningkatkan kecepatan akibat beralihnya volume lalu lintas pada jalan tersebut. Hal ini dikarenakan semakin rendah volume lalu lintas maka kecepatan akan semakin meningkat dan juga sebaliknya semakin tinggi volume lalu lintas maka semakin rendah kecepatan arus lalu lintas. Begitu juga dengan arus lalu lintas pada Ruas Jalan Tol Sigli - Banda Aceh.

\subsection{Waktu Tempuh Dan Kecepatan}

Tabel 4 memperlihatkan hasil dari waktu tempuh dan kecepatan kendaraan pada ruas jalan eksisting.

Tabel 4 Waktu tempuh dan kecepatan kendaraan untuk ruas eksisting

\begin{tabular}{ccccc}
\hline \multirow{2}{*}{ No } & Jenis Kendaraan & \multicolumn{3}{c}{ Kondisi Eksisting } \\
\cline { 3 - 5 } & Golongan I (LV) & $\begin{array}{c}\text { Jarak } \\
(\mathbf{k m})\end{array}$ & $\begin{array}{c}\text { Kecepatan } \\
(\mathbf{k m} / \mathbf{j a m})\end{array}$ & $\begin{array}{c}\text { Waktu Tempuh Rata- } \\
\text { Rata Hitungan (jam) }\end{array}$ \\
\hline 1 & Golongan IIA (MHV) & 110 & 48.2 & 2.282 \\
\hline 2 & Golongan IIB (LT \& LB) & 110 & 42.8 & 2.570 \\
\hline 3 & & & 33.3 & 3.303 \\
\hline
\end{tabular}

Tabel 5 memperlihatkan hasil dari waktu tempuh dan kecepatan kendaraan untuk ruas jalan tol

Tabel 5 Waktu tempuh dan kecepatan kendaraan untuk ruas Jalan Tol

\begin{tabular}{ccccc}
\hline \multirow{2}{*}{ No } & Jenis Kendaraan & \multicolumn{3}{c}{ Kondisi Setelah dibangun Jalan Tol } \\
\cline { 3 - 5 } & Golongan I (LV) & $\begin{array}{c}\text { Jarak } \\
(\mathbf{k m})\end{array}$ & $\begin{array}{c}\text { Kecepatan } \\
(\mathbf{k m} / \mathbf{j a m})\end{array}$ & $\begin{array}{c}\text { Waktu Tempuh Rata-Rata } \\
\text { Hitungan (jam) }\end{array}$ \\
\hline 1 & Golongan IIA (MHV) & 75 & 80 & 0,938 \\
\hline 2 & Golongan IIB (LT \& LB) & 75 & 80 & 0,938 \\
\hline 3 & & & 80 & 0,938 \\
\hline
\end{tabular}

Dari tabel 4 dan tabel 5 memperlihatkan hasil dari kedua waktu tempuh dan kecepatan yang didapat pada kedua ruas jalan, yang dapat di gunakan sebagai perbandingan antara kedua ruas tersebut maka dari kedua perbandingan tersebut dapat diambil kesimpulan bahwa ruas Jalan Tol Sigli - Banda Aceh dapat menghemat waktu perjalanan daripada Jalan Existing. 


\subsection{Penghematan Nilai Waktu}

Seperti yang dikutip dari (LAPI-ITB, 1997), nilai waktu di definisikan sebagai nilai uang yang rela dikeluarkan oleh seseorang, dalam hal ini pengguna jalan tol, untuk menghemat/memperoleh suatu unit waktu dari hasil keputusannya untuk menggunakan jalan alternatif tol ketimbang jalan biasa. Penghematan nilai waktu perjalanan dalam penelitian ini merupakan salah satu keuntungan lain dari pembangunan Jalan Tol Banda Aceh - Sigli. Penghematan nilai waktu dalam penelitian ini di dapat dari nilai waktu tempuh rata rata di kalikan dengan nilai waktu orang dan di tambah dengan nilai waktu kendaraan, dan kemudian hasil dari perhitungan penghematan nilai waktu ruas jalan eksisting kemudian di kurangkan dengan hasil penghematan nilai waktu dari ruas jalan tol sigli banda aceh. Hasil untuk penghematan nilai waktu untuk kendaraan Golongan I (LV) di jalan eksisting adalah sebesar Rp 226.759,- /kendaraan, nilai waktu mobil penumpang dijalan alternatif tol sebesar $\mathrm{Rp}$ 93.151,-/kendaraan. Selisih nilai waktu atau penghematannya untuk mobil penumpang antara jalan eksisting dan Jalan Tol Banda Aceh - Sigli adalah sebesar Rp 133.607,-/kendaraan.

Penghematan Nilai Waktu untuk Golongan IIA (MHV) di jalan eksisting sebesar Rp1.639.469-/kendaraan, nilai waktu bus di Jalan Banda Aceh - Sigli sebesar Rp 598.034,-/kendaraan. Penghematan nilai waktu untuk Golongan IIA (MHV) antara jalan eksisting dan jalan alternatif dengan Jalan Tol Banda Aceh Sigli sebesar Rp 1.041.436,-/kendaraan.

Penghematan Nilai Waktu untuk Golongan IIB (LT \& LB) di jalan eksisting sebesar Rp 247.751,-/kendaraan, nilai waktu Golongan IIB (LT \& LB) di Jalan Banda Aceh - Sigli sebesar Rp 70.313,-/kendaraan. Selisih nilai waktu untuk truk antara jalan eksisting dan Jalan Banda Aceh - Sigli sebesar Rp 177.438/kendaraan. Hasil perhitungan Penghematan Nilai Waktu untuk masing-masing ruas selengkapnya dapat dilihat pada Tabel 6 .

Tabel 6 Nilai waktu kendaraan pada jalan eksisting (with Non Tol) dan jalan alternatif (with Tol Banda Aceh-Sigli).

\begin{tabular}{|c|c|c|c|c|c|c|c|c|}
\hline \multirow{3}{*}{ No } & \multirow{3}{*}{$\begin{array}{l}\text { Ruas } \\
\text { Jalan }\end{array}$} & \multirow{2}{*}{\multicolumn{3}{|c|}{ Waktu Tempuh (jam) }} & \multicolumn{3}{|c|}{ Nilai Waktu } & \multirow[t]{2}{*}{$\begin{array}{c}\text { Total } \\
\text { Nilai Waktu }\end{array}$} \\
\hline & & & & & $\begin{array}{l}\text { Gol I } \\
\text { (LV) }\end{array}$ & $\begin{array}{l}\text { Gol IIA } \\
\text { (MHV) }\end{array}$ & $\begin{array}{c}\text { Gol IIB } \\
\text { (LT \& } \\
\text { LB) }\end{array}$ & \\
\hline & & $\begin{array}{l}\text { Gol I } \\
(L V)\end{array}$ & $\begin{array}{l}\text { Gol IIA } \\
\text { (MHV) }\end{array}$ & $\begin{array}{c}\text { Gol IIB } \\
(\text { LT \& LB) }\end{array}$ & Rp/Kend & Rp/Kend & Rp/Kend & Rp/Kend \\
\hline 1 & Eksisting & 2.282 & 2.570 & 3.303 & 226.759 & 1.639 .469 & 247.751 & 2.113 .979 \\
\hline 2 & Alternatif & 0,938 & 0,938 & 0,938 & 93.151 & 598.034 & 70.313 & 761.498 \\
\hline \multicolumn{2}{|c|}{ Selisih Nilai } & 1.345 & 1.633 & 2.366 & 133.607 & 1.041 .436 & 177.438 & 1.352 .480 \\
\hline
\end{tabular}

\subsection{Biaya Operasional Kendaraan (BOK)}

Selain manfaat berupa waktu tempuh yang lebih singkat saat melewati Jalan Lintas Banda Aceh - Sigli (Ruas Jalan Lambaro - Bts. Pidie dan Bts. Pidie/Aceh Besar - Bts. Kota Sigli), penghematan BOK juga merupakan salah satu keuntungan lainnya yang didapat dengan dibangunnya jalur alternatif Jalan Banda Aceh - Sigli. seperti yg di jelaskan pada halaman 4, biaya operasi kendaraan terdiri dari dua komponen utama yaitu biaya tidak tetap (variable cost atau running cost) dan biaya tetap (standing cost atau fixed cost), (Tamin, 2008).untuk biaya tidak tetap (variable cost atau running cost) yang di jelaskan pada halaman 
4 dan di hitung menggunakan persamaan 2 pada halaman 5 dan untuk komponen biaya tetap (standing cost atau fixed cost) terdapat penjelasannya pada halaman 5 dan di hitung dengan menggunakan persamaan 3 yang terdapat pada halaman 5 . Dari hasil penelitian didapatkan BOK untuk Golongan I (LV) di jalan eksisting sebesar Rp 2.307,-/kendaraan/km dan Jalan Banda Aceh - Sigli sebesar Rp $1.828,-/ \mathrm{kendaraan} / \mathrm{km}$. Penghematan BOK yang didapat dari kedua alternatif rute jalan untuk Golongan I (LV) sebesar Rp 479,-/kendaraan/km. BOK untuk Golongan IIA (MHV) dijalan eksisting sebesar Rp 5.341 ,-/kendaraan/km dan untuk Jalan Banda Aceh - Sigli sebesar Rp 4.068,-/kendaraan $/ \mathrm{km}$. Penghematan BOK yang didapat dari kedua rute jalan untuk Golongan IIA (MHV) sebesar Rp 1.273,-/kendaraan/km, sedangkan BOK untuk Golongan IIB (LT \& LB) dijalan eksisting sebesar Rp 4.758 ,-/kendaraan/km dan untuk Jalan Banda Aceh - Sigli sebesar Rp3,692,-/kendaraan/km. Penghematan BOK yang didapat dari kedua rute jalan untuk Golongan IIB (LT \& LB) sebesar Rp 1.066,-/kendaraan/km. Besarnya selisih BOK dari kedua ruas tersebut dapat dilihat pada Tabel 7.:

Tabel 7 Biaya Operasional Kendaraan (BOK) Sigli-Banda Aceh

\begin{tabular}{ccccc}
\hline \multirow{2}{*}{ No. } & \multirow{2}{*}{ Jenis Kendaraan } & BOK jalan existing & BOK jalan alternatif & Selisih BOK \\
\cline { 3 - 5 } & & $(\mathbf{R p} / \mathbf{k e n d} . \mathbf{k m})$ & $(\mathbf{R p} / \mathbf{k e n d} . / \mathbf{k m})$ & $(\mathbf{R p} / \mathbf{k e n d} . / \mathbf{k m})$ \\
\hline 1 & Golongan I (LV) & 2.307 & 1.828 & 479 \\
\hline 2 & Golongan IIA (MHV) & 5.341 & 4.068 & 1.273 \\
\hline 3 & Golongan IIB (LT \& LB) & 4.758 & 3.692 & 1.066 \\
\hline
\end{tabular}

\subsection{Besar Keuntungan Biaya Operasional Kendaraan (BKBOK)}

Penentuan tarif dibatasi maksimum 70\% dari BKBOK, (Suhartono, Dkk, 2010) Dari hasil penelitian didapat Besar Keuntungan Biaya Operasional Kendaraan (BKBOK) untuk Golongan I (LV) di dapat sebesar Rp. 124.701 untuk Golongan IIA (MHV) di dapat sebesar Rp. 307.707 dan untuk Golongan IIB (LT \& LB) di dapat sebesar Rp.276.656 Untuk lebih jelas besarnya Besar Keuntungan Biaya Operasional Kendaraan (BKBOK) tersebut dapat dilihat pada Tabel 8.

Tabel 8 Besar Keuntungan Biaya Operasional Kendaraan (BKBOK)

\begin{tabular}{cccccccccc}
\hline \multirow{2}{*}{ No } & \multirow{2}{*}{ Jenis Kendaraan } & \multicolumn{2}{c}{ BOK (Rp) } & $\mathbf{D}(\mathbf{k m})$ & $\begin{array}{c}\text { Tv } \\
(\mathbf{R p} / \mathbf{j a m})\end{array}$ & $\mathbf{V}(\mathbf{k m} / \mathbf{j a m})$ & $\begin{array}{c}\text { BKBOK } \\
(\mathbf{R p})\end{array}$ \\
\cline { 3 - 10 } & & BOK $_{\text {ekst }}$ & $\mathbf{B O K}_{\text {baru }}$ & $\mathbf{D}_{\text {ekst }}$ & $\mathbf{D}_{\text {baru }}$ & & $\mathbf{V}_{\text {ekst }}$ & $\mathbf{V}_{\text {baru }}$ \\
\hline 1 & Gol I (LV) & 2.307 & 1.828 & 110 & 75,00 & 6.000 & 48,20 & 80,00 & $\mathbf{1 2 4 . 7 0 1}$ \\
\hline 2 & Gol IIA (MHV) & 5.341 & 4.068 & 110 & 75,00 & 15.493 & 42,80 & 80,00 & $\mathbf{3 0 7 . 7 0 7}$ \\
\hline 3 & Gol IIB (LT \& LB) & 4.758 & 3.692 & 110 & 75,00 & 12.760 & 33,30 & 80,00 & $\mathbf{2 7 6 . 6 5 6}$ \\
\hline
\end{tabular}

Untuk maksimum 70\% dari keuntungan BKBOK didapat untuk Golongan I (LV) di dapat sebesar Rp. 87.290 dari keuntungan BKBOK untuk Golongan IIA (MHV) di dapat sebesar Rp. 215.395 dan untuk Golongan IIB (LT \& LB) di dapat sebesar Rp.193.659. Untuk lebih jelasnya Rekap Rencana Tarif Tol Berdasarkan $70 \%$ dari BKBOK dapat dilihat pada Tabel 9.

Tabel 9 Rekap Rencana Tarif Tol Berdasarkan $70 \%$ dari BKBOK

\begin{tabular}{clcc}
\hline NO & Jenis Kendaraan & BKBOK (Rp) & $\mathbf{7 0 \%}$ \\
\hline 1 & Golongan I (LV) & $\mathbf{1 2 4 . 7 0 1}$ & $\mathbf{8 7 . 2 9 0}$ \\
\hline 2 & Golongan IIA (MHV) & $\mathbf{3 0 7 . 7 0 7}$ & $\mathbf{2 1 5 . 3 9 5}$ \\
\hline 3 & Golongan IIB (LT \& LB) & $\mathbf{2 7 6 . 6 5 6}$ & $\mathbf{1 9 3 . 6 5 9}$ \\
\hline
\end{tabular}

Studi Penentuan Tarif Tol Rencana Ruas Jalan Tol Banda Aceh - Sigli - Qasim Hisbul Wathan, Muhammad Isya, Sugiarto Sugiarto 


\section{Kesimpulan dan Saran}

\subsection{Kesimpulan}

Beberapa kesimpulan yang dapat diambil berdasarkan analisis yang dilakukan pada penelitian ini dengan menggunakan metode Pacific Consultant International (PCI) untuk penentuan BOK dan untuk penentuan Tarif Jalan Tol Sigli - Banda Aceh berdasarkan $70 \%$ dari BKBOK sebagai berikut:

1. Penghematan biaya operasional kendaraan (BOK) jika lalulintas melewati Jalan Tol Sigli - Banda Aceh sebesar Rp. 1,828,-/kendaraan untuk golongan I (LV), Rp. 4.068,-/kendaraan untuk golongan IIA (MHV) dan Rp. 3,692,/kendaraan untuk golongan IIB (LT \& LB).

2. Penghematan Waktu Tempuh Perjalanan yg di peroleh jika arus lalulintas melewati Jalan tol sebesar 0,938 jam untuk kendaraan golongan I (LV), untuk golongan IIA (MHV) dan untuk golongan IIB (LT \& LB). Dapat di simpulkan manfaat pada arus lalu lintas pada jalur eksisting akan meningkatkan kecepatan akibat beralihnya volume lalu lintas pada jalan tersebut. Hal ini dikarenakan semakin rendah volume lalu lintas maka kecepatan akan semakin meningkat dan juga sebaliknya semakin tinggi volume lalu lintas maka semakin rendah kecepatan arus lalu lintas. Begitu juga dengan arus lalu lintas pada Ruas Jalan Tol Sigli - Banda Aceh.

3. Penghematan nilai waktu perjalanan yang diperoleh jika arus lalulintas melewati jalur Jalan Tol Sigli - Banda Aceh adalah sebesar Rp. 93,151,/kendaraan untuk golongan I (LV), Rp. 598,034,-/kendaraan untuk golongan IIA (MHV) dan Rp. 70,313,-/kendaraan untuk golongan IIB (LT \& LB).

4. Dalam perencanaan tarif jalan tol penentuan tarif dibatasi maksimum $70 \%$ BKBOK yaitu sebesar Rp. 87.290 untuk $75 \mathrm{Km}$ dari panjang Jalan Tol Banda Aceh - Sigli, atau sebesar Rp. 1.164 ,- jika di bagi per kilometernya untuk kendaraan golongan I (LV), sebesar Rp. 215.395 untuk $75 \mathrm{Km}$ dari pajang Jalan Tol Banda Aceh - Sigli, atau sebesar Rp. 2.872 jika di bagi per kilometernya untuk kendaraan golongan IIA (MHV), sebesar Rp. 193.659 untuk $75 \mathrm{Km}$ dari pajang jalan tol sigli - banda aceh, atau sebesar Rp. 2.582 jika di bagi per kilometernya untuk kendaraan golongan IIB (LT \& LB).

\subsection{Saran}

Berikut ini diberikan beberapa saran untuk kesempurnaan penelitian diantaranya:

1. Untuk mendapatkan nilai manfaat yang lebih banyak terhadap pembangunan Jalan Tol Banda Aceh - Sigli sebaiknya manfaat terhadap parameter lain seperti dampak terhadap lingkungan dan ekonomi masyarakat juga perlu diperhitungkan agar hasil yang didapatkan lebih memuaskan.

2. Disarankan pada penelitian selanjutnya untuk melakukan Perhitungan Analisis Investasi Finansial/keuangan dan nilai ekonomi untuk dapat menentukan tarif Jalan Banda Aceh - Sigli yang ideal.

3. Juga disarankan pada penelitian selanjutnya untuk melakukan kajian kelayakan dari aspek mitigasi bencana, aspek kecelakaan dan aspek biaya operasi kendaraan.

4. Diharapkan penelitian ini dapat menjadi acuan dan bahan pertimbangan untuk pihak-pihak yang terkait dalam menentukan tarif Jalan Tol Banda Aceh - Sigli 


\section{Daftar Kepustakaan}

Departemen Pekerjaan Umum, 2005, Pedoman Perhitungan Biaya Operasi Kendaraan, Puslitbang Prasarana Transportasi, Jakarta.

Undang-undang Republik Indonesia. Peraturan Pemerintah Nomor 15 Tahun 2005 tentang jalan tol, Jakarta.

Kementerian Pekerjaan Umum Republik Indonesia, 1997, Manual Kapasitas Jalan Indonesia, Highway Capacity Manual Project

Lembaga Afiliasi Penelitian Dan Industri Institut Teknologi Bandung (LAPIITB), 1997. Studi Perhitungan Nilai Waktu PT. Jasa Marga. Bandung.

Menteri Pekerjaan Umum dan Perumahan Rakyat. 2015. Peraturan Menteri Pekerjaan Umum dan Perumahan Rakyat Nomor : 248/KPTS/M/2015 tentang Penetapan Ruas Jalan Dalam Jaringan Jalan Primer Menurut Fungsinya Sebagai Jalan Arteri (JAP) Dan Jalan Kolektor-1 (JKP-1). Menteri PUPR, Jakarta.

Menteri Perhubungan, 2015. Peraturan Menteri Perhubungan Nomor : PM 111 Tahun 2015 tentang Tata Cara Penetapan Batas Kecepatan, Jakarta.

Metode Perhitungan Biaya Operasional Kendaraan, Pacific Consultant International (PCI).

Suhartono,dkk (2010). Modul PRJL-III Perencanaan Lalu Lintas Dan EkonomiTransportasi. Himpunan Pengembangan Jalan Indonesia (HPJI). Jakarta.

Tamin, O. Z., (2008), Perencanaan, Permodelan, dan Rekayasa Transportasi Contoh Soal dan Aplikasi, Penerbit ITB, Bandung. 